\title{
Discrimination against older people
}

\author{
Wim JA van den Heuvel \\ Department of Public Health, University of Groningen, The Netherlands
}

\section{Summary}

The increasing number of old people is becoming a growing policy concern. Negative attitudes towards old people raise questions about the extent to which discrimination against old people exists and elder abuse occurs. This paper describes the occurrence of discrimination against old people and elder abuse, as well as the factors related to it, based on a review of (scientific) literature, official documents and the actions of legal bodies.

Frequent or regular age discrimination, as experienced by old people themselves, is reported by a quarter of European citizens. Data on elder abuse vary and are often not representative; the same goes for data on inequality. Nevertheless, the analysis shows that discrimination against old age and elder abuse occurs regularly in the 'western world'. Vulnerable old people are especially at risk. National and regional, multi-component action plans are recommended to combat discrimination against old people.

Key words: discrimination, old age, abuse, ageism.

\section{Introduction}

Although the ageing of societies is a process that started a long time ago, its consequences have not been realised by policy makers until recently. Ageing of societies is a unique and positive development of mankind. It is a major demographic transition that will cause - as all major transitions - significant societal changes, insecurity and conflicts of interest. ${ }^{1,2}$ Ageing of societies creates opportunities, but also raises questions and challenges. ${ }^{3}$ Questions arise about social assistance, accessible, quality (health) care, and old age pensions. Such questions and the continuing growth in numbers of old people may create or stimulate negative attitudes and discrimination against people in old age. The problem of being old in various, especially

Address for correspondence: Professor Wim J.A. van den Heuvel, Heggerweg 2a, 6176 RB Spaubeek, The Netherlands. E-mail: heuvelwim@hotmail.com developed, societies is increasing dependence, loss of respect, experienced loneliness and discrimination. ${ }^{3-5}$ 'Full citizenship' is at risk for old people, especially for the frail old.

Ageing is recognized as a threat for (developed) societies because of the expected increase to them of costs (pensions and care) and the lack of personnel for productive work, reducing economic growth, endangering both general welfare and care for the frail old. ${ }^{2}$ Such negative expectations may stimulate intergenerational conflicts, including exclusion of old citizens. Indeed, the citizens becoming old now (the baby boomers) are portrayed as having taken their children's future and that they should pay it back. ${ }^{6}$ Not surprisingly, an overwhelming negative attitude towards old citizens is reported, for example in the United States. ${ }^{7}$ In Europe, age in general is most frequently mentioned as reason for discrimination. ${ }^{8}$ Stereotypes of old people and the ageing process are not uncommon in society at large. ${ }^{9}$

Given the increasing number of old people, the expressed policy concerns about it, and negative attitudes towards old people, the question is raised about to what extent discrimination against old people exists these days.

Respect for the old is believed to diminish in 'western' culture. A European study reports that old Europeans stated that they receive more respect than less, and the very old stated that they more often receive respect. ${ }^{10}$ However, the data show the ambivalence of EU citizens when it comes to respect for old citizens. It was also found that older citizens (55 years and older) were more likely to see negative attitudes towards their age group in their country than younger ones. ${ }^{11}$ In other cultures, such as in South-East Asia and India, respect for the old is strongly embedded in family and social life. ${ }^{12,13}$

If old citizens are perceived negatively and less respected and the increase in numbers of the old is described as a 'tsunami', they may become 'unwanted' and discrimination against them may 
increase. In such a process, exclusion of old citizens may become 'normal' and full participation of the old is not welcomed. It is stated that discrimination against older people presents a major barrier to any ambition for active ageing. ${ }^{14}$ However, it has to be realised that the relationship between what people think or say and do is not that strong. ${ }^{15}$ Additionally, discrimination because of old age may differ from other types of discrimination. ${ }^{16}$ Since citizens often have positive and negative stereotypes about old people, their behaviour may be positive and negative, i.e. showing helping behaviour as well as excluding behaviour. ${ }^{16}$ Old citizens may experience positive as well negative behaviours, which may even differ within old citizens.

This paper intends to present evidence about discrimination against old people. Before doing so, the concept of age discrimination has to be clarified and the method of finding evidence will be described.

\section{The concept of age discrimination}

Age discrimination is related to two other phenomena, i.e. 'ageism' and 'elder abuse'. Robert Butler coined the word 'ageism'. ${ }^{4}$ Ageism consists of a combination of prejudicial and negative attitudes towards old people and the process of ageing, institutional regulations that confirm stereotypes about old people and the exclusion of (services/treatment/help to) old people. ${ }^{17}$ The concept of ageism is broad and linked both with elder abuse and age discrimination, but also to attitudes, stereotypes, legislation and structure. Elder abuse and age discrimination may both be seen as expressions of ageism: behaviours that disadvantage or mistreat old people because of their age. Both (age) discrimination and (elder) abuse may occur in various situations (family, work, leisure) in which the social-cultural and institutional context 'allow' such behaviour, i.e. ageism.

Elder abuse is described in various ways. The most common definition may be: 'a single or repeated act or lack of appropriate action, occurring within any relationship where there is an expectation of trust, which causes harm or distress to an older person'. ${ }^{18,19}$ Abuse of old people can be divided into: physical abuse; psychological abuse; financial or material abuse; or sexual abuse. ${ }^{20}$ Elder abuse is a form of age discrimination.
Ageism leads to discrimination according to European 'Equality Bodies'. ${ }^{14}$ Discrimination is defined as the unjust or prejudicial treatment of different categories of people, especially on the grounds of race, gender, religion, sexual orientation and/or age. In the context of civil rights, discrimination refers to unfair or unequal treatment of an individual or group based on certain characteristics. Discrimination is a comparative concept, i.e. a person or group is treated 'worse'/'unfairly' compared with other people or groups because of a specific characteristic ascribed to this person or group. ${ }^{21}$ Various behaviours and actions indicate discrimination, but they have in common that they exclude or reject the other. Discrimination based on age is often related to discrimination on other grounds. ${ }^{14}$

Discrimination is the outcome of a complex process in which a person, a group, or a category of people are differentiated on assumed or real characteristics and/or specific beliefs, while differentiation based on such characteristics and/or beliefs is seen societally as unjustified. ${ }^{22}$ The way discrimination is exposed may be direct, i.e. explicitly and openly directed to people with the characteristic(s), or indirect. This means that discrimination may be assessed directly, i.e. observing and/or questioning the (extent of) discriminating actions and behaviours, or indirectly, i.e. analysing the consequences of specific actions, measures or behaviours on their adverse effects. Statistical data and registration systems may show age discrimination indirectly. Verbal antagonism, avoidance, physical aggression and extermination are indicators of direct discrimination.

In many countries legal arrangements are created to combat discrimination. Legislation to combat age discrimination is mostly part of a wider legislation on human rights and/or equal treatment. The presence of such legislation is seen as institutional action against discrimination.

\section{Methods}

This review intends to report data on discrimination against old people and abuse of old people, showing the evidence of age discrimination. Ageism is a widespread phenomenon across the European Union. ${ }^{14}$ However, the criteria used to assess the extent of ageism, or in this review the 
extent of discrimination and abuse in old age, are less clear. There is no set of valid and reliable instruments to assess the extent of discrimination or abuse. To find 'strong' evidence, we looked for data derived from scientific articles and official documents. A literature search resulted in a limited number of articles (MeSH terms: discrimination, abuse, ageism and elderly). Searching in MEDLINE and PsychLIT with 'discrimination' and 'abuse', the number of papers was 195. Inspection of the abstracts showed that a limited number were dealing with old people. In the case of official documents the sources of the data - and therefore the reliability - were not always clear. Most studies were found by snowball sampling of the literature.

One method, which was selected in this review, was to consider data based on direct questions to old people about whether they experience discrimination because of their age. The question about experienced discrimination presents less subjective information than when people are asked whether they feel discriminated against because of their age. Also, by asking old people themselves rather than others (family, citizens, professionals) the situation reflects what is actually happening in old people's lives.

However, not all old people will report age discrimination for various reasons (fear, denial, customs). This will be even more so in case of elder abuse. The literature shows that elder abuse more frequently occurs to people in a vulnerable situation. This situation makes it difficult for people to express their opinion. Therefore, we also used an additional source, i.e. discrimination and abuse of old people because of age reported to official bodies like committees for equal treatment, police, consumer organizations and courts, as far as available.

Another way to look for evidence of age discrimination is to use information based on structured questionnaires sent to various experts such as researchers, practitioners, social workers, representatives of non-governmental organizations (NGOs) and policy makers. However, if such questionnaires are open, the outcomes represent a wide variety of definitions, descriptions and explanations without a theoretical and empirical context. ${ }^{23}$ As a consequence, it might be impossible to relate the results to the research question.

Legislation can be a cause for age discrimination, as is described under ageism. So, another way to look at age discrimination is to analyse specific legislation on age discrimination. In this review a short description will be given of two major legislation initiatives.

\section{Data on discrimination and abuse}

Overall, $42 \%$ of citizens in the European Union think age discrimination is widespread, with $52 \%$ saying it is rare. Differentiation between countries shows that age discrimination is believed to be widespread by citizens of Hungary $(67 \%)$, the Czech Republic (58\%) and Slovakia (49\%), and not to be so widespread by citizens in Romania (30\%), Denmark (28\%) and Ireland and Luxembourg (both 24\%). ${ }^{24}$ Older people stated more often that discrimination is widespread in their country than younger people. ${ }^{24}$

When EU citizens are asked more specifically about those situations where people have been discriminated against because of old age, it is found that workplace age discrimination $(6 \%)$ is the most frequently reported form of age discrimination experienced by EU citizens, followed by age discrimination in access to financial products and services $(5 \%)$ and age discrimination in health care $(4 \%)$. The proportion of EU citizens who report to have witnessed such age discrimination in the workplace is $15 \%$, for access to financial products and services is $10 \%$ and for health care is $11 \% .^{11}$

Age discrimination in the workplace also includes job seeking. A survey among 700 registered job seekers found that $80 \%$ of them feel that they have been discriminated against because of their age during their job search. ${ }^{25}$ No wonder that over $90 \%$ of jobseekers over 50 years feel that the policy makers are ignoring the problem.

In health care, there is the danger of underdiagnosis and under-treatment in old people, because health problems and symptoms in old people may be overlooked or dismissed as part of the normal aging process. $^{9}$ Opinions, including those of health care professionals, are that age discrimination exists structurally in health care. ${ }^{26-28}$ Under-diagnosis and undertreatment because of old age may be seen as age discrimination, but precise data are lacking.

Old people in Europe also report experienced discrimination because of their age. Whilst a majority $(52 \%)$ state that they have never been discriminated against, $15 \%$ report to have been sometimes and $11 \%$ frequently 
discriminated against. ${ }^{5}$ Significant differences exist between European countries; a relatively high proportion of old people report having experienced discrimination recently because of their age in the Czech Republic (23\%), Ukraine (20\%), Russia $(18 \%)$, Romania (16\%), Bulgaria $(11 \%)$ and Slovakia $(11 \%)$, and a relatively low proportion in Sweden $(2 \%)$, Denmark (2\%), Norway $(3 \%)$ and Switzerland $(3 \%)$.

The World Health Organization estimates that $4-6 \%$ of older people worldwide have suffered from a form of elder abuse - either physical, psychological, emotional, financial or due to neglect. ${ }^{29}$ A systematic review of 94 studies showed that $6 \%$ of older people in the general population reported significant abuse. ${ }^{30}$ When these researchers selected studies with only validated instruments to assess abuse, they found that about a quarter of the vulnerable old reported serious psychological abuse. Among home care staff, $16 \%$ admitted significant psychological abuse. However, reporting abuse was significantly lower when abuse was recorded using objective measures. The authors conclude that one in four vulnerable old people are at risk of abuse and only a small proportion of this is currently detected. The UK National Prevalence Study of Elder Mistreatment among independent living elderly, using a face-to-face questionnaire, found that almost $3 \%$ reported mistreatment by family members, close friends or care workers. ${ }^{31}$

Elder abuse is reported more frequently in residential settings than domestic settings. Various investigations show that psychological abuse is often occurring in nursing homes (in about in 8 of 10 cases), as reported by staff members. ${ }^{32-35}$

Complaints/cases related to age discrimination reported to Equality Bodies in various European countries vary between 3 and $20 \%$ of all complaints/cases: $20 \%$ in Austria, $17 \%$ in Germany, Lithuania and The Netherlands, 15\% in France, $10 \%$ in Denmark and Hungary, $8 \%$ in the Czech Republic, 7\% in Luxembourg, 5\% in Belgium and 3\% in Bulgaria, Ireland and the United Kingdom. ${ }^{14}$

Most complaints about discrimination are related to employment (advertisements, access, recruitment, dismissal, retirement). Beyond employment, the most frequent complaints concern access to insurance and banking services (consumer credits, credit cards, loans, mortgages and accounts). Age discrimination related to housing, social protection, social care and health care is less often reported to Equality Bodies. ${ }^{14}$

\section{Factors and conditions related to age discrimination}

Socio-economic (gender, occupation, marital status) and social factors (poverty, housing conditions, social network and social contacts), as well as societal factors (stereotypes, prejudice, mistrust between generations) may be related to age discrimination and therefore be seen as risk factors for discrimination against the old. ${ }^{7,15}$ Generally, gender and socio-economic status have been found to be correlated with age discrimination. Various studies suggest that age discrimination occurs in cases of poor health and dependency. ${ }^{28,36}$ A study in the UK among independent living elderly people showed that women, people with a low socio-economic position and those with worse health status are more likely to be mistreated. ${ }^{31}$

People who believe that discrimination occurs frequently also report more frequently that they experience discrimination. ${ }^{37}$ People who feel safe and have trust in other people may perceive less discrimination than those who do not. Attitudes are often seen as being related to the tendency to discriminate. Beliefs and attitudes are often internalized as stereotypes of a specific culture, which results in implicit discrimination..$^{38,39}$ The socio-cultural context people live in may also influence age discrimination. For example, discrimination of old people is more frequent in Eastern European countries and rare in Scandinavian countries. ${ }^{5}$ This socio-cultural context is given as one explanation for the big differences in experienced discrimination in old citizens between European countries. ${ }^{5}$

Age discrimination in health care is reported worldwide $^{40}$ Lack of geriatric training may cause inequity in clinical treatment, because staff members have little knowledge of the specific care needs of older people. Stress related to care giving is another factor that may cause age discrimination and abuse. As mentioned, elder abuse is reported more frequently in residential settings than domestic settings. However, in at least one study it was found that family members were responsible for abuse in the majority of the cases. ${ }^{35}$ However, elder abuse in nursing homes is a persistent phenomenon. ${ }^{41}$ 
A review in 18 developed countries showed that many physicians have negative attitudes and stereotype beliefs towards old people. ${ }^{42}$ It may be not remarkable then that older people are significantly under-represented in clinical trials.

\section{Legislation on age discrimination}

The USA has a long-standing body of legislation on age discrimination. ${ }^{43}$ The first age discrimination law in 1967 was related to employment. The Age Discrimination in Employment Act (ADEA) protects applicants and employees of 40 years and older from discrimination on the basis of age in hiring, promotion, discharge, compensation, or terms, conditions or privileges of employment. In 1975 the Age Discrimination Act (ADA) was adopted. It is directed to prohibit age discrimination in programmes and activities receiving federal financial assistance. The ADA, which applies to all ages, permits the use of certain age distinctions. In the Workforce Investment Act (WIA) of 1998, a special section (188) deals with discrimination against applicants, employees and participants in WIA financially assisted programmes and activities.

The European Commission (EC) formulated an Anti-Discrimination Framework Directive to combat discrimination and stimulate equal treatment ${ }^{44}$ establishing a general framework for equal treatment in employment and occupation. The council framework directive requires member states to implement laws to combat various forms of discrimination including discrimination on the grounds of religion or belief, sexual orientation, disability and age. The Anti-Discrimination Framework Directive effects age discrimination legislation in all Member States. However, interpretations, claims of discriminations and sanctions do vary between member states. Implementation of such directives takes time.

The legislation on age discrimination raises questions about its impact and consequences on employment, the labour market, access to health care, etc. Analyses indicate that the ADEA has resulted in later retirement and more older workers in the USA. ${ }^{45}$ The effect of the EC framework directive is the subject of a (scientific) debate. Age discrimination legislation may have a significant massive impact on the employment relationship and pension schemes, resulting in changes of the established retirement ages. ${ }^{46}$ In Europe, the national responses to the EC directive are believed not to be effective due to a utilitarian perspective and weak implementation. ${ }^{47}$

\section{Discussion}

This paper questioned the extent of discrimination against old people. This question is related to discussions about respect for old people and the barriers of full participation of old citizens, to the reports and findings about 'social welfare problems' because of ageing of societies, and to the negative perceptions about old age (at least in some cultures). Notwithstanding the methodological weaknesses in assessing age discrimination, to be discussed later, it may be concluded that age discrimination and elder abuse are problems that occur regularly in ageing societies.

Exact figures cannot be presented, but about a quarter of old people probably do experience discrimination regularly because of their old age. ${ }^{5}$ This proportion is significantly higher among the dependent old, of whom a significant proportion live in institutions. For older people living in institutions, discrimination and abuse seem to be more the rule than the exception.

Age discrimination is more often witnessed than it is reported. Age discrimination occurs relatively frequently in workplace settings and job seeking. It is witnessed more frequently - and is probably easier to notice - in the workplace and in health care than in financial and service settings, but the data show that it may occur in all settings and the data do not indicate large differences between settings.

The proportion of reports on age discrimination to European Equality Bodies is rather low. Besides selection, this could be related to the belief that discrimination because of old age is (still) judged as normal or justifiable. ${ }^{14}$ Such beliefs sustain a culture where old people accept or even do not recognize discrimination. In the UK, the Department of Work and Pensions concluded that age-related discrimination and stereotyping remain 'rooted in British society'. The large difference in experienced discrimination by old people because of their age between European countries underlines the explanation that age discrimination is embedded in state-welfare culture. ${ }^{5}$

Some authors state that the existence of elderly abuse, especially of those who are very dependent, is well documented. ${ }^{48}$ Certainly we have 
concluded that it occurs regularly and - in specific conditions - often. However, we found that data on age discrimination and elder abuse are rather scarce in scientific literature and official documents. The sources of the data in official documents are not always clear. Besides, these data are sometimes rather old. The data in the report of the United Nations of 2010, presenting a 'comprehensive overview', uses data that are ten years old.

Available data may be questioned because of representativeness and reliability. For example, old people who do lodge a complaint with Equality Bodies will be a specific group. The variation in reported elder abuse using different instruments questions the validity of the way data are collected. It is recommended that a validated set of instruments to assess age discrimination and elder abuse should be developed. ${ }^{30}$

To combat age discrimination, it is not enough to have reliable data or registration systems. It is important to understand the factors and mechanisms that are related to age discrimination. Four factors seem to be important to consider: socio-demographic factors, personal characteristics, social-environmental factors and state-welfare conditions and culture. Age discrimination occurs more frequently if people are poor and less educated, have a worse health status, no confidence in other people and lack of network/social support, and are living in a country with poor social-welfare provisions and abuse of justice. It may be no surprise that in East European countries, where discrimination against old age is experienced more frequently, the majority of all citizens state that their country is not 'age-friendly', i.e. not adapted to the needs of old people. ${ }^{11}$

Discrimination is most difficult to deal with when it is indirect, the result of apparently neutral rules that adversely affect a particular group. Human rights are, by definition, universal and apply to all citizens, including older people. ${ }^{40}$ Human rights, which are needed to combat discrimination, are therefore formulated very broadly. References to older people are not found or understood easily. International documents may perform an interpretive function in this regard. Various conventions formulate these implicitly, for instance: The International Covenant on Economic, Social and Cultural Rights and the International Covenant on Civil and Political Rights, the Convention on the Elimination of All Forms of Discrimination against Women, the International Convention on the Elimination of All Forms of Racial Discrimination and the Convention on the Rights of Persons with Disabilities. So, age is a prohibited ground of discrimination.

The Human Rights Committee of the United Nations is not in favour of an additional convention specific to old age and it is not needed according to the Report of the Secretary-General. ${ }^{40}$ Neither a specific UN committee, nor a UN rapporteur on rights of older people, is considered as an option in the report, but reliable data are needed to show and prove the discrimination. Being aware of the myths and realities of ageing is as important as facts about discrimination. ${ }^{9}$ Once the difference between facts and fictions are clear, more specific measures are needed.

An Expert Group proposes the following measures to fight discrimination against old age: formulate policy and make public statements, create awareness, register age discrimination and stimulate research on old age discrimination and elder misuse, design and implement comprehensive prevention programmes, and supply information for older adults about their rights. ${ }^{4}$ Although still vague, such recommendations make sense. Legislation and human rights are not enough to combat age discrimination. Facts and effective interventions have to be available.

A measure like a national ombudsman or national committee on the rights of older people may be more controversial. Maybe the most effective way to combat discrimination against old people is to stimulate and facilitate full participation of older people in societal and policy decision-making processes. This option may be not unrealistic: four out of ten EU citizens want old citizens to play a bigger role in their country. ${ }^{11}$

This analysis on the factors and conditions related to discrimination against old age shows that one size does not fit all. Each country and all institutional bodies have to find measures to combat age discrimination. So each country and body should take responsibility. However, there is one common prerequisite: these measures have to be multi-component.

\section{Conclusions}

At the beginning of this century, the United Nations reported that prosecution because of discrimination is rare in most countries. ${ }^{49}$ In 
the case of discrimination against old people this situation may be especially poor. It was also stated that whatever legislation there is will be ineffective as long as cases are not prosecuted. However, one measure is not enough. What is needed is a multi-component action plan, supported internationally, executed and operationalized nationally and regionally. It is urgently needed because discrimination against old age occurs regularly. The components of such a plan are described. ${ }^{40}$ Within such an action plan, concern for vulnerable old people is a priority. Special measures in health care settings are needed for old people, including training, quality control and increase of expertise.

Discrimination against old people and elder abuse will be with us for some time, but can be defeated. The legislation and the instruments are available. The idea that old people could and should play a bigger role in their country is supported by a significant number of citizens. So, there is potential in manpower and attitudes. Ideas how to put this into action are numerous, but should be used in a comprehensive, strategic plan. Above all, old people themselves are challenged to show how they want to contribute to the human development of their society.

\section{Conflict of interest}

The author confirms that he has no conflicts of interest.

\section{References}

1 OECD. Help wanted? Providing and paying for long-term care. Paris: OECD report, 2011.

2 van den Heuvel WJA. Value reorientation and intergenerational conflicts in ageing societies. J Philosophy Med 2012 (in press).

3 Harper S. Ageing Societies. London: Hodder Education, 2006.

4 Butler R. Why Survive? Being Old in America. New York: Harper and Row, 1975.

5 van den Heuvel WJA, van Santvoort M. Experienced discrimination among European old citizens. Eur J Ageing 2011; 8: 291-99.

6 Willetts D. The Pinch. How baby boomers took their children's future - and why they should give it back. London: Atlantic Books, 2010.

7 Bishop JL, Roden BK, Bolton AC, Wynn RV. An assessment of the relationships among attitudes toward the elderly, death anxiety, and locus of control. Psychology Program, Department of Behavioral and Social Science, University of Montevallo, Montevallo. Presentation at Dominican University of California, 2008.

8 Eurobarometer 317. Discrimination in the EU in 2009. Special Eurobarometer Report 317. Brussels: European Commission, 2009.

9 Salzman B. Myths and realities of aging. Care Management J 2006; 7: 141-50.

10 Walker A. Age and attitude. Brussels: European Commission, 1993.

11 Eurobarometer 378. Active Ageing. Special Eurobarometer Report 378. Brussels: European Commission, 2012.

12 Papol N. Attitudes of Thai people towards old age. Available at: http://www.onlineijra.com/ research\%20paper/a/.pdf (accessed 18 April 2012).

13 Ingersoll-Dayton B, Saengtienchai C. Respect for the elderly in Asia: stability and change. Int $J$ Aging Human Dev 1999; 48: 113-30.

14 Tackling Ageism and Discrimination. An Equinet Perspective. September 2011, ISBN 978-92-95067-56-1.

15 Vernon AE. Designing for change: attitudes toward the elderly and intergenerational programming. Child Youth Services 1999; 20 : 161-73.

16 Cuddy AJC, Norton MI, Fiske ST. The old stereotype: the pervasiveness and persistence of the elderly stereotype. J Social Issues 2005; 61: 265-83.

17 Wilkinson J, Ferraro K. Thirty Years of Ageism Research. In Nelson T (ed), Ageism: Stereotyping and Prejudice Against Older Persons. Cambridge MA: Massachusetts Institute of Technology, 2002.

18 World Health Organization (WHO)/INPEA. Missing voices: views of older persons on elder abuse. Geneva: WHO, 2002.

19 Gutman G, Spencer C (eds). Aging, Ageism and Abuse: Moving from Awareness to Action. Amsterdam: Elsevier, 2010.

20 Report of the Expert Group Meeting, 'Rights of Older Persons'. United Nations Department of Economic and Social Affairs Division for Social Policy and Development Programme on Ageing, Germany, 2009.

21 Horta O. Discrimination in terms of moral exclusion. Theoria: Swedish J Philosophy 2010; 76: 346-64.

22 Wait S, Midwinter E. Promoting age equality in health care. London: A report for the Alliance for Health and the Future, 2005.

23 van Bavel M, Janssens K, Schakenraad W, Thurlings N. Elderly abuse in Europe. Background and Position Paper 01062010. 
Utrecht: The European Reference Framework Online for the Prevention of Elder Abuse and Neglect (EuROPEAN), 2010.

24 Eurobarometer 296. Discrimination in the European Union. Perceptions, Experiences and Attitudes. Special Eurobarometer Report 296. Brussels: European Commission, 2008.

25 http://www.agediscrimination.info/News/Pages/ ItemPage.aspx?Item=613 (accessed 3 April 2012).

26 Age Concern. Ageism in Britain. An age concern research briefing. London: Age Concern Policy Unit, 2008.

27 Williams PW. Age discrimination in the delivery of health care services to our elders. Faculty Publications Paper 79, Marquette University Law School, 2009.

28 Clarke A. Ageism and age discrimination in primary and community health care in the United Kingdom. London: Centre for Policy on Ageing, 2009.

29 World Health Organization. Abuse of the elderly. Geneva: WHO, 2002. Available at: www.who.int/ violence_injury_prevention/violence/world_report/ factsheets/en/elderabusefacts.pdf.

30 Cooper C, Selwood A, Livingston G. The prevalence of elder abuse and neglect: a systematic review. Age Ageing 2008; 37: 151-60.

31 Biggs S, Manthorpe J, Tinker A, Doyle M, Erens B. Mistreatment of older people in the United Kingdom: findings from the first National Prevalence Study. J Elder Abuse Neglect 2009; 21: $1-14$.

32 Ingalls GS, Layton LT, Weitzel NB. Elder abuse originating in the institutional setting. North Dakota Law Review 1998; 74: 312-39.

33 Pillemer K, Moore DW. Highlights from a study of abuse of patients in nursing homes. J Elder Abuse Neglect 1990; 2: 5-29.

34 Georgen T. Stress, conflict, elder abuse, and neglect in German nursing homes: a pilot study among professional caregivers. J Elder Abuse Neglect 2001; 13: 1-26.

35 Weatherall M. Elder abuse: a survey of managers of residential care facilities in Wellington, New Zealand. J Elder Abuse Neglect 2001; 13: 91-99.

36 Pascoe EA, Richman LS. Perceived discrimination and health: a meta-analytic review. Psychol Bulletin 2009; 135: 531-54.
37 Salentin K. Determinants of experience of discrimination in minorities in Germany. Int $J$ Conflict Violence 2007; 1: 32-50.

38 Mossakowski KN. Coping with perceived discrimination: does ethnic identity protect mental health? J Health Social Behav 2003; 44: 318-31.

39 Adams A, Buckingham CD, Arber S, McKinlay JB, Marceau L, Link C. The influence of patient's age on clinical decision-making about coronary heart disease in the USA and the UK. Ageing Society 2006; 26: 303-322.

40 Report of the Secretary-General. Follow-up to the Second World Assembly on Ageing: comprehensive overview. New York: UN General Assembly 2010.

41 Castle N. Nursing home deficiency citations for abuse. J Appl Gerontol 2011; 30: 719-43.

42 Safiliou-Rothschild C. Age-based inequalities in medical treatment. AARP International J 2010; Winter: 56-59.

43 http://www.dol.gov/dol/topic/discrimination/ agedisc.htm (accessed 19 April 2012).

44 Council Directive 2000/78/EC of 27 November 2000. Brussels: European Commission, 2012.

45 Neumarkt D. Age discrimination legislation in the United States. Working Paper 8152. Cambridge, USA: National Bureau of Economic Research, 2001.

46 O'Mailly B. Age discrimination in Irish employment law. Industrial Law Society (ILS) Spring Conference in London, 2010.

47 O'Cinneide C. Comparative European perspectives on age discrimination legislation. Available at: http://www.ippr.org/uploadedFiles/ projects/comparison.doc\&sa $=\mathrm{X} \&$ scisig $=$ AAGBfm38FJG7LIPyWvtHxmOsLGuutNpf_ Q\&oi=scholarr\&ei=e9KOT9SvEoagOoLsqe8K\& ved=0CB0QgAMoADAA 2002 (accessed 11 April 2012).

48 Teaster PB, Anetzberger GJ. Elder abuse in contemporary society: programs, policy, and politics. J Elder Abuse Neglect 2010; 22: 3-5.

49 Discrimination. Extract from the Report on the World Social Situation 1997, chapter VIII presented by Larry Willmore, United Nations Department of Economic and Social Affairs. New York: United Nations Expert Group Meeting on Managing Diversity in the Civil Service United Nations Headquarters, 2001. 